\title{
FORMAÇÃO DOCENTE: REFLEXÕES SOBRE O PROJETO DOCÊNCIA COMPARTILHADA
}

\author{
Matheus Morais da Luz (Mestrando em Educação - UEM) \\ matheuspeduem94@hotmail.com \\ Renan Valério Eduvirgem (Mestrando em Geografia - UEM) \\ georenanvalerio@gmail.com \\ Pedro Felipe Barbosa (Ciências Sociais - UEM) \\ pedro.fb19@yahoo.com.br \\ Prof $^{\mathrm{a}} \operatorname{Dr}^{\mathrm{a}}$ Sandra Maria Coelho de Souza Moser (Orientadora)
}

"Antes de tudo, a educação não é uma propriedade individual, mas pertence por essência à comunidade” (Werner Jaeger-Paidéia)

\section{RESUMO}

O presente artigo tem por objetivo contextualizar a análise da experiência, enquanto participante do Projeto Docência Compartilhada no Colégio de Aplicação Pedagógica da Universidade Estadual de Maringá (CAP-UEM). Primeiramente faremos a exposição dos objetivos e ações do Projeto Docência Compartilhada. Em seguida serão esboçadas as ações realizadas pelos participantes do projeto, juntamente ao CAP-UEM, pensando as suas práticas metodológicas. Na sequência serão analisadas as propostas dos mesmos no âmbito Colégio onde se realizou tais práticas, pensando nas contribuições das mesmas para a formação, tanto do aluno do Colégio, como também da formação profissional do acadêmico de licenciatura. As práticas foram desenvolvidas por meio dos participantes do projeto de forma integrada, sendo: aluno do Colégio, Universidade, equipe pedagógica e professores não somente do Colégio, mas como também da Universidade. Busca-se refletir criticamente sobre a importância de tal projeto para formação acadêmica do futuro profissional em educação, bem como do possível pesquisador em educação.

Palavras-chave: Educação, docência, professor.

\begin{abstract}
This article aims to contextualize the analysis of the experience, as a member of the Shared Teaching Project on Educational Application of College of the State University of Maringa (CAP-UEM). First we will make the presentation of the objectives and actions of the Shared Teaching Project. Next will be outlined the actions taken by the project participants together to CAP-UEM, thinking their methodological practices. Following will analyze the proposals of the same scope in the College where they held such practices, considering the contributions of the same for the formation of both the college student as well as the training of academic degree. The practices were developed by participants in an integrated fashion design, as follows: Student College, University, teaching staff and teachers not only the college but also as the University. Thus, we
\end{abstract}




\section{SEMINÁRIO DE PESQUISA EM CIÊNCIAS HUMANAS - SEPECH \\ Humanidades, Estado e desafios didático-científicos \\ Londrina, 27 a 29 de julho de 2016}

expected to think about the importance of such a project for academic training of future professionals in education, as well as the possible research in education.

Key words: Education, teaching, teacher.

\section{CARACTERÍSTICAS GERAIS SOBRE O PROJETO NO CAP-UEM}

Em sua base, o Projeto Docência Compartilhada objetiva garantir aos alunos do Colégio de Aplicação Pedagógica da Universidade Estadual de Maringá (CAP-UEM) um trabalho continuado de modo que todos os sujeitos envolvidos no processo de ensino-aprendizagem se tornem participantes ativos do processo, construindo assim uma experiência coletiva entre professor e aluno.

Essa experiência coletiva parte inicialmente do professor, o qual no caso da Docência Compartilhada se trata como monitor. Os monitores são estudantes de graduação da Universidade Estadual de Maringá, quase que exclusivamente da área de licenciatura, que sob um contrato com a Universidade recebe um pagamento ("bolsa trabalho") para realizar as atividades no CAP-UEM.

Esses monitores, por meio do Projeto, vivenciam o cotidiano do trabalho docente e as imbricações que envolvem o mesmo, o que os possibilita receber uma formação em ação. Nesse movimento recíproco de aprendizagem é que o projeto se torna significativo tanto aos monitores como aos alunos do CAP-UEM.

Em síntese, os monitores eram responsáveis por preparar e aplicar aulas sobre conteúdos universais às turmas do Ensino Fundamental e Ensino Médio quando algum professor se ausentasse da instituição, com a supervisão das coordenações do projeto.

\section{BREVES RELATOS DAS EXPERIÊNCIAS}

Para entender melhor a proposta do projeto de Docência Compartilhada do CAPUEM, se faz necessário a exposição das experiências vividas no ambiente escolar, através de breves relatos. Iniciaremos com as observações e apontamentos de Matheus Morais da Luz, por ser um dos primeiros a fazer parte do projeto e ter permanecido maior tempo. Em seguida, as considerações de Renan Valério Eduvirgem e Pedro Felipe Barbosa.

\subsection{Relato de Matheus}

Durante os primeiros sete meses em que estive no CAP-UEM exerci a função que auxiliar de Coordenação, o que foi muito enriquecedor para minha formação. Durante este período todas as manhãs eu auxiliava as duas Coordenadoras dos Anos Finais do Ensino Fundamental em todas as suas atividades, desde a recepção dos alunos até o termino do período.

Depois de sete meses auxiliando a coordenação me removeram para o turno da tarde para fazer o acompanhamento das series iniciais do ensino fundamental. Inicialmente minha função era apenas acompanhar as duas turmas do $4^{\circ}$ ano, porém muitos professores me solicitavam para auxiliá-los em algumas atividades. Desta forma 


\section{SEMINÁRIO DE PESQUISA EM CIÊNCIAS HUMANAS - SEPECH \\ Humanidades, Estado e desafios didático-científicos \\ Londrina, 27 a 29 de julho de 2016}

ao longo de minha permanência nessa função me deparei com todos os anos das series iniciais, desde o $1^{\circ}$ ano até o $5^{\circ}$ ano. Essa alternância nas turmas, por mais que tornava o trabalho difícil, por não ter certa continuidade, me deu a possibilidade de conhecer todas as turmas e de participar de atividades práticas com todas elas.

Tendo permanecido como auxiliar de sala das series iniciais por quatro meses, novamente me transferiram para uma nova atividade. Desta vez, passei a fazer parte do Projeto Aulas Vagas, o qual foi implantado com o intuito de solucionar o problema de aulas vagas que o CAP-UEM estava passando. Esse projeto ocorria da seguinte maneira: na ausência do professor um monitor assumia a turma, ou seja, todas as vezes que um professor faltava os alunos passavam a ter aula com um monitor. O Projeto Aulas Vagas serviu de esboço para o Projeto Docência Compartilhada, do qual fiz parte um ano até a meu desligamento.

\subsection{Relato de Renan}

Mediante a realização de trabalho, o Projeto Docência Compartilhada no CAPUEM proporciona ao acadêmico uma pequena bolsa, tipo um "salário"; contribui para o desenvolvimento de potencialidades vinculadas ao exercício da docência, com cursos de capacitação teórico-práticos e da própria atuação em sala de aula.

Este projeto vai para além do estágio, permitindo ao acadêmico avançar nas análises e atuações no processo de ensino-aprendizagem, inclusive com maiores compromissos e responsabilidades. Pois, no estágio obrigatório o acadêmico cumpre uma carga horária limitada, que nem sempre possibilita aprofundar em certas questões escolares.

A experiência de ter participado deste projeto jamais será esquecida, pois ampliou e enriqueceu a formação teórico-prática da docência dentro da própria dinâmica escolar. Foi uma forma de adquirir e compartilhar conhecimento, por meio de mecanismos didático-pedagógicos para aplicação de aulas temáticas para turmas do ensino fundamental e médio.

\subsection{Relato de Pedro}

Antes de tudo, a experiência no CAP-UEM me colocou na condição de trabalhador, pois, não era apenas bolsa, mas sim trabalho remunerado pelo tempo dedicado na instituição - "bolsa trabalho" como é conhecido. Entre os meses de $11 / 2015$ e 02/2016 atuei como monitor para as turmas do ensino fundamental e médio, conforme a necessidade do colégio, além de prestar auxílio à coordenação/direção.

Foi um período que contribuiu para uma melhor compreensão do exercício teórico-prático de "ser professor", privilegiando a vivência concreta da prática docente, e não apenas as questões abstratas. Diversos temas relacionados à realidade históricosocial puderam ser trabalhados com as variadas turmas, sempre de maneira crítica, reflexiva e com a finalidade de compreender algumas das contradições da nossa sociedade capitalista contemporânea, tais como: exploração do trabalho pelo capital, lutas de classes e alienação, machismo e violência contra a mulher, racismo, movimentos sociais e a luta por direitos, o caso de Mariana-MG e a precarização no mundo do trabalho, a questão do terrorismo. Quando entrava em sala para "cobrir aula 


\section{SEMINÁRIO DE PESQUISA EM CIÊNCIAS HUMANAS - SEPECH \\ Humanidades, Estado e desafios didático-científicos \\ Londrina, 27 a 29 de julho de 2016}

vaga" - o que ocorria quase que diariamente, pois muitos professores se ausentavam, vários por motivo de saúde -, fazia ser uma aula com leituras, análises, debates e até produção de textos, provocando o jovem estudante a pensar sobre o tema proposto.

Eram aulas diferenciadas, sem peso avaliativo burocrático, que visavam ser construídas coletivamente, problematizando questões sociais concretas como mecanismos de reflexão e participação. Apesar dos limites, era um trabalho de docência que envolvia seleção de temas/conteúdos, leitura de textos/materiais, preparação de aulas/atividades e atuação em sala. Ocupar o espaço da sala de aula era uma forma de provocar o conhecimento sobre aspectos do nosso tipo de sociabilidade, assumindo sempre a perspectiva crítica e classista de transformação social.

\section{PARA NÃO CONCLUIR. A SALA DE AULA COMO ESPAÇO PARA FAZER A CRÍTICA À SOCIEDADE DE CLASSES, AO ESTADO E AO CAPITAL, POR UMA EDUCAÇÃO TRANSFORMADORA}

Com base na teoria social marxista, precisamos compreender, antes de tudo, que no capitalismo as relações sociais de trabalho estão estruturadas sob a forma de trabalho assalariado, de compra-e-venda da força de trabalho dos trabalhadores pelos capitalistas, gerando, assim, uma sociedade baseada em classes sociais, na propriedade privada, no lucro e na exploração do homem pelo homem. Entender que capital e trabalho são elementos antagônicos e, portanto, as mudanças históricas que ocorrem no mundo do trabalho não são homogêneas nem harmônicas, mas, ao contrário, é necessariamente uma totalidade contraditória, antagônica, desigual e conflituosa em sua essência. Um processo de dominação e exploração do trabalho pelo capital.

As observações e atuações durante todo o período em que estivemos inseridos na realidade do CAP-UEM nos fez analisar criticamente a questão educacional no conjunto da sociedade, compreendendo que a educação está diretamente articulada à dinâmica do Estado burguês e ao modo de produção capitalista. O Estado burguês, inserido na lógica capitalista, assume um papel fundamental na manutenção da contraditória, antagônica, desigual e conflituosa forma de sociabilidade que vivemos, como um meio de garantir a reprodução do Capital em todas as esferas da ordem social. Pois, conforme as análises do pesquisador marxista Mauro Iasi (2013):

O Estado é a trincheira de proteção estratégica da ordem da propriedade privada e da acumulação privada da riqueza socialmente produzida. No centro desta zona estratégica está a classe dominante, a grande burguesia monopolista dona de fábricas, bancos, empresas de transporte, controlando o comércio interno e externo, o agronegócio, as indústrias farmacêuticas e das empresas de saúde etc. (IASI; 2013)

E, conforme Marx e Engels (2010) em o Manifesto Comunista:

A burguesia não pode existir sem revolucionar incessantemente os instrumentos de produção, por conseguinte, as relações de produção e, com isso, todas as relações sociais. [...] Impelida pela necessidade de mercados sempre novos, a burguesia invade todo o globo terrestre. Necessita estabelecer-se em toda a parte, explorar em toda a parte, criar vínculos em toda a parte. [...] Pela exploração do mercado mundial, a 


\section{SEMINÁRIO DE PESQUISA EM CIÊNCIAS HUMANAS - SEPECH \\ Humanidades, Estado e desafios didático-científicos \\ Londrina, 27 a 29 de julho de 2016}

burguesia imprime um caráter cosmopolita à produção e ao consumo em todos os países. (MARX, ENGELS; 2010, p. 43)

Assim, a educação, enquanto uma política social controlada pelo próprio Estado burguês, tem na reprodução do capital a tônica do seu desenvolvimento (Ivo Tonet, 1998). Nessa perspectiva temos como base para a compreensão da educação a dinâmica que se dá na sociedade capitalista como um todo. Trata-se de uma dinâmica totalmente contraditória e crítica, caracterizada pela flexibilização da produção e pela consequente flexibilização de todas as relações sociais nesse tipo de sociedade, inclusive na esfera educacional.

Ao se propor a compreender e refletir sobre a realidade da educação na atualidade, se faz necessário analisar, antes de tudo, o contexto histórico ao qual ela está inserida, bem como qual é a função adquirida por ela dentro desse contexto. Hoje vivemos em um contexto onde a produção se tornou flexível, as mercadorias e objetos se tornaram flexíveis o que exige da classe trabalhadora maior flexibilização do trabalho, ou melhor, a divisão social do trabalho se flexibiliza e precariza para atender a produção capitalista. Cabe, aqui, destacar a afirmação de Harvey:

A acumulação flexível [...] é marcada por um confronto direto com a rigidez do fordismo. Ela se apóia na flexibilidade dos processos de trabalho, dos mercados de trabalho, dos produtos e padrões de consumo. Caracteriza-se pelo surgimento de setores de produção inteiramente novos, novas maneiras de fornecimento de serviços financeiros, novos mercados e, sobretudo, taxas altamente intensificadas de inovação comercial, tecnológica e organizacional. A acumulação flexível envolve rápidas mudanças dos padrões de desenvolvimento desigual, tanto entre setores como entre regiões geográficas, criando, por exemplo, um vasto movimento no emprego no chamado "setor de serviços", bem como conjuntos industriais completamente novos em regiões até então subdesenvolvidas. (HARVEY, 2001, p. 140, apud. GALUCH; SFORNI, 2011, p.57)

Inserida nesse processo de produção e possuindo como principal objetivo a reprodução e perpetuação desse sistema, a educação é em síntese o reflexo e o resultado do modo de produção capitalista. Assim, atendendo os ditames do capitalismo, a educação se limita a formação de sujeitos flexíveis e adaptáveis à dinâmica de exploração do mercado de trabalho, por mais que em seus planos constem a ideia de "emancipação humana". Para exemplificar e fazer a crítica, temos as Diretrizes Curriculares da EJA do Estado do Paraná que diz o seguinte:

A emancipação humana será decorrência da construção dessa autonomia obtida pela educação escolar. O exercício de uma cidadania democrática pelos educandos da EJA será o reflexo de um processo cognitivo, crítico e emancipatório, com base em valores como respeito mútuo, solidariedade e justiça. (PARANÁ, 2006, p. 29)

Ainda que essas e muitas outras diretrizes do Estado burguês sinalizem para um ensino que proporcione a compreensão das relações contraditórias entre capital e trabalho, a realidade demonstra que isso não ocorre, tendo em vista que a educação, na estrutura capitalista, simplesmente serve de base para a manutenção desse sistema, não 


\section{SEMINÁRIO DE PESQUISA EM CIÊNCIAS HUMANAS - SEPECH \\ Humanidades, Estado e desafios didático-científicos \\ Londrina, 27 a 29 de julho de 2016}

pretendendo alcançar de fato a emancipação do ser social. Pois, na perspectiva marxista, a emancipação se dará somente em outra forma de sociabilidade humana, totalmente diferente do capitalismo.

Feito essas fundamentais observações, torna-se imprescindível relaciona-las a ação dos monitores no projeto Docência Compartilhada. Importante destaque a ser feito é o fato de mesmo que o projeto esteja inserido nessa realidade educacional, ele possibilita aos monitores maior abertura para uma abordagem critica dos temas/conteúdos relacionados à nossa realidade histórico-social. Apesar dos limites do próprio projeto, se torna possível desenvolver e aplicar propostas que busquem não a manutenção e reprodução da lógica capitalista, mas sim o conhecimento crítico deste sistema social. Mesmo concordando com a visão de Instván Mészáros de que "[...] é necessário romper com a lógica do capital se quisermos contemplar a criação de uma alternativa educacional significativamente diferente" (MÉSZAROS, 2008, p. 27), compreendemos o projeto como um meio de disputa política e ideológica de consciência, de análise concreta da realidade concreta, que contribua para uma formação critica da juventude. Uma formação que tenha um horizonte revolucionário e de construção de uma nova sociabilidade, realmente livre e emancipada.

\section{REFERÊNCIAS}

Diretrizes Curriculares da Educação de Jovens e Adultos. Secretaria do Estado da Educação - SEED Paraná, 2006. (Disponível na página do Portal Educacional do Estado do Paraná http://www.diaadiaeducacao.pr.gov.br; acesso em 20/02/2016).

Educação e concepções de sociedade. Disponível em < http://ivotonet.xpg.uol.com.br/arquivos/Educacao_e concepcoes_de sociedade.pdf >; elaborado em dezembro/1998; acesso em 27/01/2016.

HARVEY, David. Condição pós-moderna: uma pesquisa sobre as origens da mudança cultural. Tradução: Adail Ubirajara e Maria Stela Gonçalves. 5a . Ed. - S. Paulo: Edições Loyola, 2001.

IASI, Mauro. O Estado e a violência. Publicado em 16/10/2013. Disponível em $<$ http://blogdaboitempo.com.br/2013/10/16/o-estado-e-a-violencia/>; acesso em 06/01/2016.

MARX, Karl; ENGELS, Friedrich. Manifesto Comunista. $1^{\text {a }}$ ed. revista. São Paulo: Boitempo, 2010.

MARX, Karl. O Capital - Livro I. São Paulo: Boitempo, 2013.

MÉSZÁROS, Instván. A educação para além do capital. Tradução de Isa Tavares. $2^{\text {a }}$ ed. - São Paulo: Boitempo, 2008.

NETTO, José Paulo; BRAZ, Marcelo. Economia Política: uma introdução crítica. São Paulo: Cortez, 2006. 
XI SEMINÁRIO DE PESQUISA EM CIÊNCIAS HUMANAS - SEPECH

Humanidades, Estado e desafios didático-científicos

Londrina, 27 a 29 de julho de 2016

TONET, Ivo. Sobre o Socialismo. $2^{\text {a }}$ ed. São Paulo: Instituto Lukács, 2012. 